\title{
Eliciting the Regulation of an Economic System: the Case of the French Rail Industry
}

MARC IVALDI AND JÉRÔME POUYET 


\title{
Eliciting the Regulation of an Economic System: The Case of the French Rail Industry
}

\author{
Marc Ivaldi ${ }^{1}$ \\ Toulouse School of Economics
}

\author{
Jerome Pouyet $^{2}$ \\ Paris School of Economics
}

December 6, 2010

\begin{abstract}
Based on the modern theory of regulation, the analysis aims to characterize the effective economic regulation of the French railway industry. The methodology consists in econometrically testing various scenarios of regulation and determining which of these best fits the data.

Using aggregate data on the overall passenger traffic for the incumbent French rail operator (RO), SNCF, the two behavioral hypotheses of reference which we consider -absence of regulation of the rail operator which acts as a pure monopoly, and price regulation of services supplied by the RO- are both statistically significant and do not subtract from each other. This result is certainly related to the fact that passenger services include both high speed train services, for which the RO has some entrepreneurial freedom, and regional transport services, which are regulated by local authorities. In any case however, as the presence of unobservable efforts exerted by the RO to improve its productivity is statistically relevant, one concludes that the RO is not fully and properly regulated. This emphasizes that the design of policy reforms must account for the incentives they create on the RO.

The analysis also shows that the most statistically significant scenarios are the ones in which the access tariff imposed by the infrastructure manager is such that the revenue generated by the access tariff is equal to the infrastructure spending. The pricing of the access to the infrastructure network therefore does not seem to be governed by economic principles, but more by budget considerations.

While data limitations does neither allow to understand all the facets of a complex reality, nor to claim a high level of precision in the measure of all the parameters of interest, we believe however that we provide an objective methodology to characterize the optimal economic policies for the railway sector, in particular because it yields realistic estimates of the main structural parameters. Indeed the empirical results suggest that the railway industry as a whole exhibits increasing returns to scale, which incidentally is not compatible with the presence of multiple firms. In addition, the elasticity of demand for railway transport is relatively high, an indication of the competitive constraints this mode of transport faces from other transport modes or induced traffic.
\end{abstract}

\section{JEL codes: L51, L92}

Keywords: Regulation, Asymmetric information, Railroad industry

Acknowledgements: We would like to thank Valérie Champagne, Dominique Deaux, Jean-Louis Denizot for providing insights or comments on earlier versions. Further thanks for their helpful questions and remarks go the conference participants at the 4th Kuhmo-Nectar Conference and Summer School WZB in Valencia (July 2010) and the R\&D, Science, Innovation and Intellectual Property International Conference in Honor of Jacques Mairesse at ENSAE in Paris (September 2010). We are members of the Institut D’Economie Industrielle (IDEI) which receives research grants from a number of corporate sponsors, including SNCF. The views expressed in the paper, and any remaining errors, are solely ours.

1 Toulouse School of Economics, University of Toulouse, 21, Allée de Brienne, 31000 Toulouse. Email: marc.ivaldi@tse-fr.eu.

${ }^{2}$ Paris School of Economics, 48, Boulevard Jourdan, 75014 Paris. Email: pouyet@pse.ens.fr. 


\section{Introduction}

This article builds on the modern theory of regulation and uses econometric methods to characterize the economic regulations which effectively apply to the French railway system. Based on a data set covering the last ten years, it undertakes a statistical comparison of different theoretical regulatory models to determine which one best supports the relationship between the main variables, i.e., price, traffic and cost, characterizing the railway system.

This subject is essential to understand the potential sources of inefficiency in the system, and to eventually propose remedies, with the objective to implement an optimal economic regulation which takes into account the characteristics of the railway industry. In France, the subject has recently been the object of many reports and audits, which have analyzed the current organization of the complete system, its limitations, and the possible and preferred developments for the near future. ${ }^{1}$ All these reports tend to point to several dysfunctions, which impede the development of an efficient railway transport sector and provide inadequate long-term incentives in network development. As an attempt to tackle those issues, the French State has recently prompted the creation of a railway regulator, whose missions and powers have yet to be defined more precisely. At this stage, it is rather hazardous to evaluate the interaction between the State-owned infrastructure manager (IM), the incumbent rail operator (RO) which is vertically separated from the IM and owned by the French State, and the newly created regulator.

Our objective here is to develop a quantitative analytical tool of the functioning of the complete railway system, based on the economic concepts of asymmetric information and regulation, as developed for instance by Laffont and Tirole (1993). ${ }^{2}$ Using recent data on railway activity, this study measures structural fundamental parameters (like the aggregate elasticity of the demand for rail passenger transport services or the marginal cost of delivering these services), understands the underlying mechanisms and evaluates the actors' objectives. The model in particular explains the determination of the price of service in the railway industry, as a function of the different parameters linked to the structure of demand, costs and

\footnotetext{
${ }^{1}$ Most notably see the reports by the Inspection Générale des Finances - Conseil Général des Ponts et Chaussées (2007), the Ecole Polytechnique Fédérale de Lausanne (2007) and the Cour des Comptes (2008).

${ }^{2}$ Our text contributes to the relatively short literature on the econometrics of regulation which comprises the articles by Wolak (1994), Wunsch (1994), Gasmi, Laffont and Sharkey (1997) and Gagnepain and Ivaldi (2002) Brocas, Chan and Perrigne (2006) among others.
} 
other constraints imposed by the State, the tariff structure set by the infrastructure manager and the competitive constraints exercised by other modes of transport. To the best of our knowledge, apart from the paper by Meunier and Quinet (2009), no quantitative evaluation of the French system, based on economic principles, has ever been proposed. Meunier and Quinet's model focuses however on the analysis of infrastructure pricing; we rather deal on the whole regulation of transport services offered to passengers. Note that, although the French situation provides the background for our analysis, the methodology could be easily tailored for other countries in order to account for the features of their industry structure.

Using aggregate data on the overall passenger traffic for the French rail operator SNCF, the two behavioral hypotheses of reference which we consider -absence of regulation of the RO, which acts as a pure monopoly, and price regulation in the final sector of the ROare both statistically significant and do not subtract from each other. This result is certainly related to the fact that passenger services include both high speed train services, for which the RO has some entrepreneurial freedom, and regional transport services, which are regulated by local authorities. In any case however, the presence of unobservable efforts exerted by the RO to improve its productivity is statistically relevant in every scenario studied. In other words, the goodness-of-fit improves when one accounts for elements that cannot be directly or easily measurable like the ability of the manager, the organizational capacity or the know-how. Note that one can conclude that the RO is not fully regulated since no regulation applies on these supply variables. This emphasizes that the design of policy reforms should account for the incentives they create on the RO and should address the question of profit sharing between the State and SNCF, which is a mechanism to stimulate productivity.

In comparing different regulatory scenarios, the analysis also shows that the most statistically significant scenario is the one in which the access tariff imposed by the infrastructure manager is such that the revenue generated by the access tariff is equal to the infrastructure spending. In the recent debate on the organization of the French railway industry, one recurrent concern was the role of access pricing to provide the right economic signals to the RO. Our finding tends to confirm that access pricing is driven by budgetary concerns. In a world of bilateral monopoly, this gives rise to the double marginalization problem.

Finally, the empirical results suggest that the railway industry as a whole exhibits increasing returns to scale, which is not compatible with the presence of multiple firms. In addition, the elasticity of demand for railway transport is relatively high, an indication of the competitive constraints this mode of transport faces. 
The main limitation of our analysis comes from the limited data available. Our data are aggregated at the level of the complete system, which does not allow for a detailed analysis of different types of transport services, for example, and different authorities of regulation, be it national or regional. In addition, we do not have the information necessary to study precisely the objectives and incentives of the infrastructure manager, or the impact of the state of the network on the quality of the transport service. While data limitation does neither allow to understand all the facets of a complex reality, nor to claim a high level of precision in the measure of all the parameters of interest, we believe however that we provide an objective methodology to characterize the optimal economic policies for the railway sector, in particular because it yields realistic estimates of the main structural parameters. Indeed, the empirical results suggest that the railway industry as a whole exhibits increasing returns to scale, which is not compatible with the presence of multiple firms. In addition, the elasticity of demand for railway transport is relatively high, an indication of the competitive constraints this mode of transport faces.

\section{Data and descriptive statistics}

The economic model developed below is applied to the whole activity of passenger transport services (passage activity herein) of SNCF, which includes passenger railway travel on high speed lines (the so-called HST traffic), the main lines and regional services (including Ile-de France which is the geographical area around Paris). The data exclude freight traffic, which represented $12 \%$ of SNCF's turnover in 2008, and covers the period 2001-2008. ${ }^{3}$ Table 1 below gives the means of the main variables used in the economic analysis, with their units.

Table 1: Means of the main variables for the passenger transport services over the period 2001-2008

\begin{tabular}{cccccc}
$\begin{array}{c}\text { Passenger Traffic } \\
\text { (Billion passenger- } \\
\text { kilometers })\end{array}$ & $\begin{array}{c}\text { Capacity } \\
\text { (million train- } \\
\text { kilometers })\end{array}$ & $\begin{array}{c}\text { Service Price } \\
(€ / \mathrm{p}-\mathrm{km})\end{array}$ & $\begin{array}{c}\text { Access Price } \\
(€ / \mathrm{tr}-\mathrm{km})\end{array}$ & $\begin{array}{c}\text { Operating cost } \\
\text { RO (Billion } €)\end{array}$ & $\begin{array}{c}\text { Operating cost IM } \\
(\text { Billion } €)\end{array}$ \\
\hline 76.4 & 398 & 0.128 & 5.156 & 7.25 & 2.62 \\
\hline
\end{tabular}

Source : SNCF.

\footnotetext{
${ }^{3}$ In contrast, the relative data on the regulation of the infrastructure manager concern the complete network and activities.
} 
The passenger activity therefore includes two types of service, namely the regional traffic and the high-speed train (HST) traffic, which follow different logics. The HST traffic is not subject to a particular public intervention and seems, a priori, to respond to a purely commercial logic with a large entrepreneurial freedom. It is, however, necessary to keep in mind that SNCF is principally State-owned, and the French State can therefore exercise a certain control over the different decisions taken by this RO. The regional traffic, in contrast, is regulated as it is subject to negotiation between the rail operator and the local transport authority. The latter has the power to decide the price paid by, and the characteristics of the services offered to, final users. The logic should therefore be closer to that of a (local) planner who seeks to maximize the welfare of its constituency. These two logics must be kept in mind to determine the scenario which best corresponds to the observed data.

Figure 1 shows the change in total traffic and the capacity supplied over the period under investigation. We note that the level of traffic has strongly increased, at a rate faster than the capacity, which suggests that the rate of use of the capacity has improved.

The transport service and network access prices are respectively measured by the mean revenue per passenger-kilometer and the mean access toll per train-kilometer. ${ }^{4}$ Figure 2 shows that these prices have increased regularly throughout the period, the toll having increased by more than $50 \%$ and the transport price by $20 \%$.

On the cost side, we observe the operating costs of the rail operator and the payment received by SNCF from Réseau Ferré de France (the State-owned French Infrastructure Manager, IM) which is basically a proxy for the IM's cost. This remuneration has increased by $10 \%$ over the period during which the operating cost of the rail operator has increased by $26 \%$, as it is displayed on Figure 3.

\section{Notations and model specification}

In this section, we present the relevant economic analysis to describe the current situation of the "passenger" rail transport sector in France.

\footnotetext{
${ }^{4}$ The access toll is defined with respect to the IM's cost which covers all costs except initial and regeneration investment capital costs. Note that working with an average access price let aside the price difference across rail activities.
} 
Figure 1: Change in the capacity and the passenger traffic

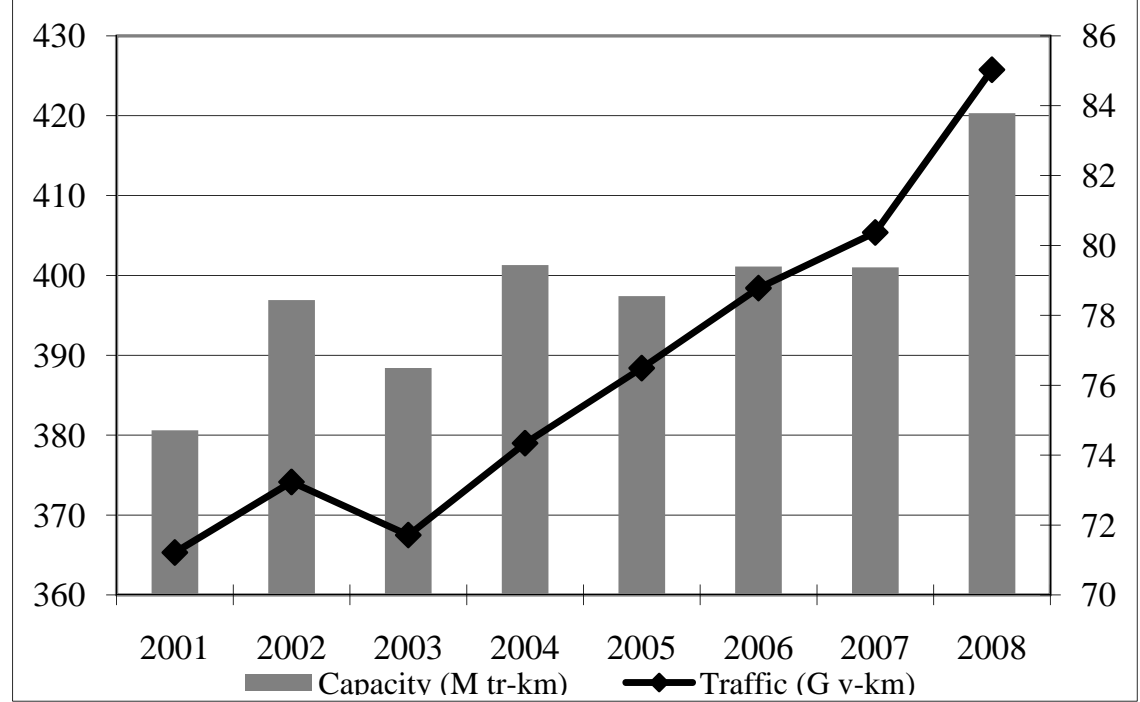

Figure 2: Evolution of the access toll and the passenger price

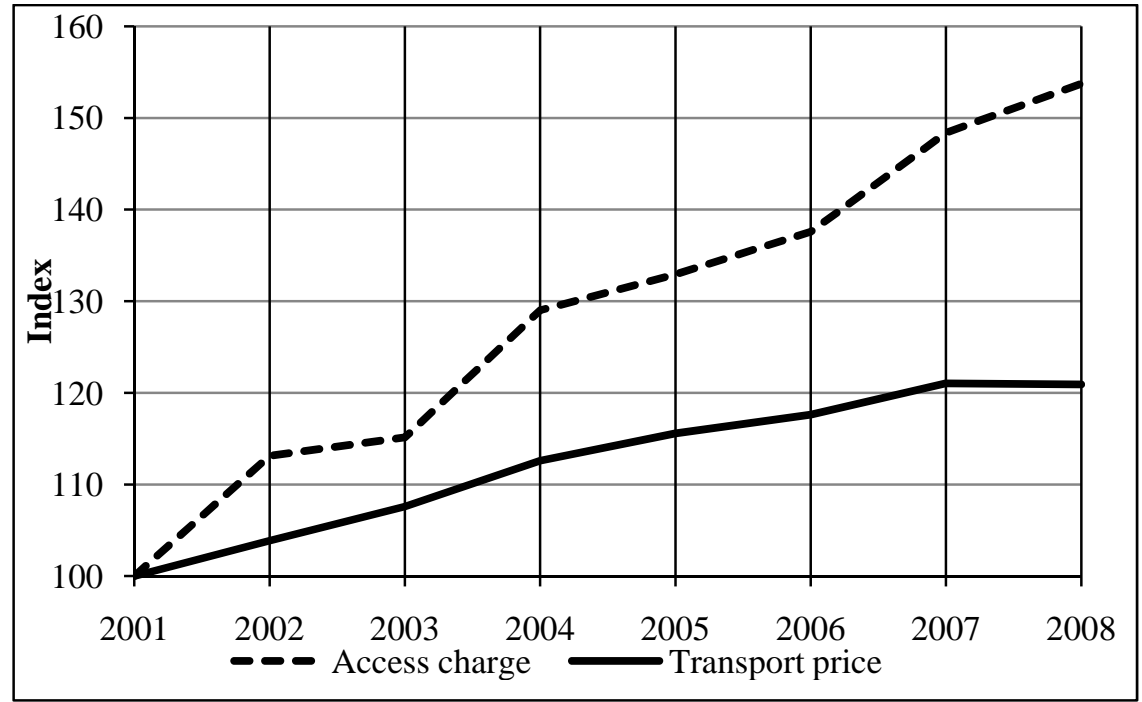

Figure 3: Evolution of the costs of the IM and the RO

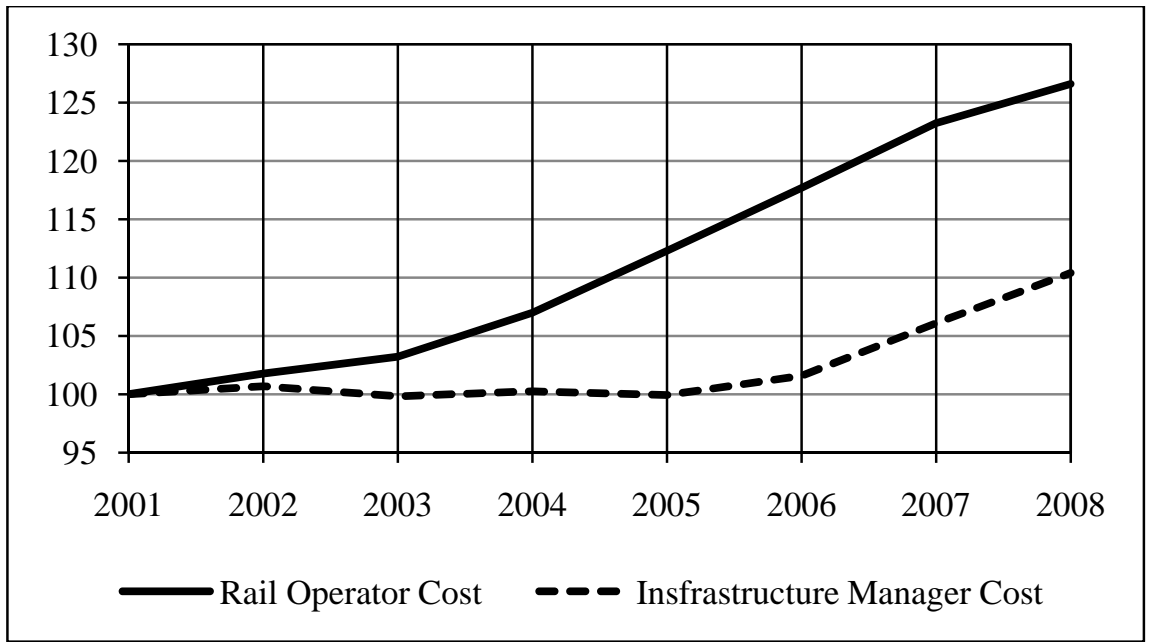




\section{The rail operator}

Let $Y$ be the supplied capacity, that is, the number of train-kilometers bought by the rail operator from the infrastructure manager. The unit price of the purchase, that is the access price, is denoted by $a$ and is expressed in euros per train-kilometer.

\section{The engineering function}

The tracks bought from the IM are used by the RO to produce a transport service for the final users. We consider here the $\mathrm{RO}$ as a single product firm. For a quantity $Y$ of bought capacity, expressed in train-kilometers, the effective quantity of transport services produced is denoted by $y$ and is expressed in passenger-kilometers. This transformation from train kilometers to passenger-kilometers is given by an "engineering function", whose precise expression is provided below.

\section{The demand function}

We consider a logit model to represent the demand for railway transport services, in which the alternatives for the user are to use or not the rail mode. When the passenger does not use the train, it means that either she/he either uses another transport mode or does not travel. The second choice is called the "outside opportunity" of the final user. The transport demand $y$ faced by the rail operator is therefore given by:

$$
\ln y=\ln y_{0}+\delta-\alpha p \text {, }
$$

where $p$ is the final price of the transport service and $y_{0}$ is the demand for the outside

alternative. The elasticity of demand is $\varepsilon(p)=\alpha p s_{0}$ where $s_{0}=\frac{y_{0}}{y+y_{0}}$ is the market share of the outside opportunity. Note that this elasticity is not constant and depends on the price of the railway transport service.

The net surplus of final users is therefore given by: $S(p)=\frac{1}{\alpha} \ln (1+\exp (\delta-\alpha p))$. We denote by $S(y)$ the gross surplus of final users, with $S(y)=S(p(y))+p(y) y$, where $p(y)$ represents the inverse demand function.

The size of the outside opportunity with respect to railway transport needs to be specified. Here we set the size of the outside opportunity to be equal to $95 \%$ of demand of 
total transport demand, essentially basing this estimate on the observation that rail transport represents around $10 \%$ of all passenger transport services in France and on the fact that only one French traveler out of two does not use trains. As a matter of fact, we tested that our results are robust to changes in the size of the outside opportunity.

\section{The cost function}

The production cost of the transport service provided by the RO is a function of the service level $y$ and an effort $e: C_{e f}(y, e)$. This effort represents either the RO's commercial activity or some unobservable actions which improve its productivity. From the cost function, one can measure the returns to scale by computing the ratio of the average cost to the marginal cost. When this ratio is greater than (respectively lower than, equal to) 1 , these returns are increasing (respectively decreasing, constant).

\section{The profit function}

The rail operator's profit is given by: $\pi_{e f}=p(y) y-a Y-C_{e f}(y, e)$, knowing that the RO must take into account the engineering function as a constraint. We note that the cost function does not take into account all the fixed costs, notably sunk costs.

\section{The infrastructure manager}

Ideally, the analysis should include the IM's cost function, which would provide the economic cost required to maintain the railway network in its current state. However the data available on infrastructure are however insufficient to allow us to identify this cost function and the objective pursued by the IM.

Hereafter, we limit ourselves to assume that the IM spends an amount $C_{g i}(Y)$ on infrastructure, assumed to be dependent on the amount of train-kilometers. The IM's revenue is given by the infrastructure charges paid by the RO, $a Y$. The IM's profit is therefore $\pi_{g i}=a Y-C_{g i}(Y)$. In our estimations, we use a linear specification for the IM's expenditure function, namely: $C_{g i}(Y)=\omega_{0}+\omega_{1} Y$.

\section{Remark}

We assume that the IM has no impact on the engineering function. The IM could have an impact on the productivity through, for example, the "quality" of the tracks provided, 
which affects the services that can be offered to final users. Likewise, the IM's spending does not affect the network quality, which is assumed to be constant in this study. These dimensions of the IM's activity should be addressed in subsequent studies, in particular when more detailed data on the IM's activity and the state of the railway network as a whole are available.

\section{The reference models}

In this section we analyze a first framework of reference in which the RO has no impact on its performance: The productivity effort is normalized to zero. The transport operator's cost is therefore given by: $C_{e f}(y)=\gamma_{0}+\gamma_{1} y$. Parameters $\gamma_{0}$ and $\gamma_{1}$ represent the rail operator's fixed and marginal cost respectively.

The engineering function is given by $Y=\beta y$, where $\beta$ is a coefficient which represents of how full the average train is per rail operator.

\section{Case of a benevolent social planner regulating a monopoly}

First of all we consider a benevolent and omniscient planner. This planner maximizes the social welfare $W$ defined as the sum of the final users' net surplus, the infrastructure manager's profit and the rail operator's profit, from which should be subtracted the taxes necessary to finance the system that are borne by the taxpayers (the final users in our context). Formally, the social welfare is written as:

$$
W=S(y)-p(y) y+\left[\pi_{e f}+T_{e f}\right]+\left[\pi_{g i}+T_{g i}\right]-(1+\lambda)\left(T_{e f}+T_{g i}\right),
$$

where $\lambda$ is the cost of public funds $T_{e f}$ and $T_{g i}$ denote the State's public contribution to the rail operator and the infrastructure manager respectively.

The cost of public funds has the following interpretation: Financing the railway system with one euro (be it through the RO or the IM) costs taxpayers $(1+\lambda)$ euros. In other words, taxation is costly and generates some distortions in the whole economy, which translates in our partial equilibrium framework to an additional cost of taxation of $\lambda$. Hereafter, the value of the cost of public funds is taken as 0.3 as it is often the case in such studies. 
The omniscient planner controls all the relevant variables for the system, that is, the final price of the transport service (or equivalently the service quantity offered by the rail operator), the amount of track access sold by the infrastructure manager, the access price, and the public subsidies to the infrastructure manager and the rail operator.

The planner must ensure that IM's and the RO's budget is balanced, that is to say $\pi_{e f}+T_{e f} \geq 0$ et $\pi_{g i}+T_{g i} \geq 0$. To minimize the fiscal charge imposed on the whole system, the subsidies to the infrastructure manager and the rail operator are adjusted so that these constraints hold with equality, that is: $\pi_{e f}+T_{e f}=0$ and $\pi_{g i}+T_{g i}=0$. Substituting the transfers obtained into the expression for social welfare gives us a new expression for social welfare:

$$
W=S(y)+(1+\lambda)\left[-C_{g i}(Y)+p(y) y-C_{e f}(y)\right] .
$$

We remark that the access price plays no role in the expression, and so the planner can perfectly control the offer of services provided to the final users and focuses on the overall profit of the industry.

Given that $y$ and $Y$ are related according to the engineering function, only one control variable remains at the disposal of the planner, $Y$ or $y$. Optimization with respect to the latter control variable produces the following optimality condition:

$$
\frac{p-\left(\frac{\partial C_{e f}}{\partial y}+\frac{\partial C_{g i}}{\partial Y} \frac{\partial Y}{\partial y}\right)}{p}=\frac{\lambda}{1+\lambda} \frac{1}{\varepsilon(p)}
$$

where $\varepsilon(p)$ is the price elasticity of the final demand which the transport operator faces. ${ }^{5}$ This condition is a Ramsey-Boiteux condition on the residual demand for the transport service: The more costly are the public funds, the greater the price which must be imposed on final consumers so as to reduce the socially costly use of public contributions. Similarly, the greater the elasticity of demand to the final price, the lower the price must be in order to minimize the distortions at the level of the user surplus. We note that the total marginal cost of service corresponds to the sum of the marginal costs of the RO and the IM weighted by the

\footnotetext{
${ }^{5}$ Its expression for the logit demand is specified above.
} 
function for the transformation of the line use into the final transport service. In effect, to produce a quantity $y$ of the final service requires the use of a quantity $Y$ of the intermediate service. We remark also that one condition which should be verified at the optimum is that the ratio $\frac{\lambda}{1+\lambda} \frac{1}{\varepsilon(p)}$ must be smaller than $1 .^{6}$

Case of a pure monopoly facing a fixed access price

We consider now the polar case in which the RO is in the position of an unregulated monopoly. The company therefore maximizes its profit, $\pi_{e f}=p(y) y-a Y-C_{e f}(y)$, under the engineering function, $Y=\beta y$. The optimality condition is therefore given by:

$$
\frac{p-\left(\frac{\partial C_{e f}}{\partial y}+a \frac{\partial Y}{\partial y}\right)}{p}=\frac{1}{\varepsilon(p)} .
$$

This condition corresponds to the "usual" monopoly optimality condition, except that here the perceived marginal cost of the rail operator is now determined in part by the access tariff. Indeed, the rail operator does not internalize the effect of its decisions on the profit of the infrastructure manager.

\section{Empirical analysis of the reference models}

We turn now to the calibration of the two theoretical situations presented in the preceding section. The procedure consists in the estimation of the parameters by fitting the corresponding system of equations to the data sample.

\section{The econometric specification}

For the two scenarios, the system to be estimated contains the same following equations:

$$
C_{g i}=\omega_{0} t+\omega_{1} Y+\tilde{v}_{1}
$$

\footnotetext{
${ }^{6}$ This condition is systematically satisfied in our estimations.
} 


$$
\begin{gathered}
C_{e f}=\gamma_{0} t+\gamma_{1} y+\tilde{v}_{2}, \\
Y=\beta y+\tilde{v}_{3}, \\
\ln y=\ln y_{0}+\left(\delta_{0}+\delta_{1} t\right)-\alpha p+\tilde{v}_{4} .
\end{gathered}
$$

Equation (6) is the infrastructure manager's cost where $\omega_{0}$ is a trend parameter and $t$ indicates the year; Equation (7) is the rail operator's cost where $\gamma_{0}$ is a trend parameter; equation (8) is the engineering function; and equation (9) is the demand function where we introduce both a trend term and a constant.

The two scenarios are distinguished by the behavioral equation to be estimated. In the case of a benevolent social planner, the behavioral equation is:

$$
p=\left(\gamma_{1}+\omega_{1} / \beta\right)+\frac{\lambda}{1+\lambda} \frac{1}{\alpha s_{0}}+\tilde{v}_{5}
$$

In the case of a rail operator in a monopoly position, the behavioral equation becomes:

$$
p=\left(\gamma_{1}+a / \beta\right)+\frac{1}{\alpha s_{0}}+\tilde{v}_{5} .
$$

In the five-equations systems, the vector $\left(\tilde{v}_{1}, \tilde{v}_{2}, \ldots, \tilde{v}_{5}\right)^{\prime}$ represents the random errors related either to measurement errors or optimization errors. We assume that these errors are independent of each other.

\section{Estimation and tests}

The two econometric models are estimated over the period 2001-2008. The five endogenous variables are the quantity of transport service $y$, the level of network use by the rail operator $Y$, the price of the transport service $p$, the production cost of the transport service, $C_{e f}$, and the infrastructure manager's costs, $C_{g i}$. The exogenous variables are the access price, $a$, and the time $t$. The different models are estimated using nonlinear three stage least squares, which implies the use of instrumental variables. The latter are chosen to be the variables lagged by one period, such as the price of transport service $p_{t-1}$ at period $t-1$ , the access price $a_{t-1}$, the network size $Y_{t-1}$ or the IM's expenditure in period $t-1$. 
The results of the estimation are presented in Table 1. Even if the number of data points is small, the good quality of estimation is achieved because the number of degrees of freedom is large enough given the number of equations to be estimated. In both cases, all the variables are statistically significant and each behavioral model produces reasonable values for the parameters of interest like the aggregate elasticity which here takes values lower than one. The two cases lead approximately to the same likelihood value, which means that statistically it is not possible to say that one model dominates the other. ${ }^{7,8}$

Our first conclusion is that the presence of regulation appears relevant for the analysis, i.e., regulation matters. This result should be expected: Since an important part of total passenger traffic is regulated by the local transport authorities and since the French State is the main shareholder of the rail operator, it is not surprising that one identifies a certain level of control over the actions of the RO.

Table 1: Estimation of the reference models

\begin{tabular}{crrrr}
\hline & \multicolumn{2}{c}{ Benevolent Planner (M1) } & \multicolumn{2}{c}{ Monopoly (M2) } \\
Parameter & \multicolumn{1}{c}{ Value } & $t$ Value & \multicolumn{1}{c}{ Value } \\
\hline$\alpha$ & 5.8127 & 5.28 & 4.1815 & 5.18 \\
$\delta_{0}$ & -2.3203 & -17.98 & -2.5098 & -26.54 \\
$\delta_{1}$ & 0.0203 & 4.92 & 0.0145 & 4.81 \\
$\beta$ & 0.0052 & 69.87 & 0.0052 & 68.69 \\
$\gamma_{0} / 10^{8}$ & 1.1004 & 5.07 & 1.0739 & 4.94 \\
$\gamma_{1}$ & 0.0896 & 71.26 & 0.0898 & 71.29 \\
$\omega_{0}$ & 15546171 & 1.70 & 14738360 & 1.53 \\
$\omega_{1}$ & 6.3928 & 62.58 & 6.4040 & 59.63 \\
\hline \multicolumn{5}{c}{} \\
\hline Elasticity & 0.7093 & & & \\
Returns to scale & 1.0572 & & 0.5102 & \\
RO’s marginal cost & 0.1225 & & 0.0554 & \\
\hline Likelihood value & 3.0412 & & 3.0773 & \\
\hline
\end{tabular}

\footnotetext{
${ }^{7}$ To be more precise, the likelihood value is the value taken by the objective function which is minimized during the process of triple nonlinear least squares estimation.

${ }^{8}$ All the models presented here are compared against each other using a specification test, namely the Vuong test. The values of this statistic can be found in a table reported in Appendix 1.
} 


\section{Moral hazard models under fixed access charge}

Now we introduce the possibility for the rail operator to increase its productivity. It takes the form of a productivity effort which is not directly measurable. This variable is not observable by the planner or the econometrician, i.e. it is a moral hazard variable. The empirical challenge is here to identify and to measure it.

In this section, we assume that the access charge is fixed, i.e., is taken as given by the $\mathrm{RO}$ and considered as such by the analyst. ${ }^{9}$

Two scenarios: Supply service regulation versus monopoly

The productivity effort, denoted by $e$, affects both the engineering function and the marginal costs of the rail operator, respectively corresponding to a better management of the demand and to a direct improvement in the productivity of the RO.

The engineering and cost functions are now written as follows:

$$
\begin{gathered}
Y=(\beta-\phi e) y, \\
C_{e f}=\gamma_{0}+\left(\gamma_{1}-e\right) y+\frac{1}{2} \gamma_{2} e^{2} .
\end{gathered}
$$

The productivity effort is costly for the rail operator, but allows to reduce its marginal cost and to increase the efficiency of the transformation of the train-kilometer into passengerkilometer through a modification of the engineering function.

The first case we consider is an intermediate scenario in which the regulator controls the rail operator's supply of services, but not its effort. The first part of this assumption seems relevant with regard to (i) the important share of regulated traffic in the data (ii) the fact that the State is the main shareholder of the RO. The second part is relevant due to asymmetries of information between the $\mathrm{RO}$ and the State which prevents the latter from completely controlling the efforts of the former. Therefore, the RO is regulated on easily observable variables (such as the supply and price of final services), but not on the unobservable dimensions, such as the productivity gains (the effort in our model).

In this situation we consider the following game: First, the State decides the supply of transport service as well as the subsidies to the railway sector; then, the RO decides its effort

\footnotetext{
${ }^{9}$ The optimality conditions for the models discussed in this section are presented in Appendix 2.
} 
level so as to maximize its profit. The optimality condition of effort for the RO leads to the following condition:

$$
e=\frac{y(1+a \phi)}{\gamma_{2}}
$$

We observe that the level of effort depends on both the access price $a$ and the service supply $y$. Recall that the access price is considered as exogenous -it cannot be changed by the planner to affect the behavior of the rail operator.

By solving the planner's choice of the supply of services, we obtain the following optimality condition: ${ }^{10}$

$$
\frac{p-\left(\frac{\partial C_{e f}}{\partial y}+\frac{\partial C_{g i}}{\partial Y} \frac{\partial Y}{\partial y}\right)}{p}=\frac{\lambda}{1+\lambda} \frac{1}{\varepsilon(p)}+\frac{1+a \phi}{\gamma_{2}} \frac{y}{p} \phi\left(a-\omega_{1}\right)
$$

This condition can be interpreted as follows. The left hand term corresponds to the price-cost margin, i.e., the margin of the final price over the marginal cost of the whole service, this marginal cost being the sum of the RO's and IM's marginal costs. The right hand side breaks down into two terms. The first corresponds to the inverse of the price elasticity of demand weighted by the cost of public funds. The second term comes from the fact that the regulator anticipates the impact of the choice of service offer on the effort choice made by the rail operator. In effect, the effort of the rail operator is not at its socially optimal level because the RO does not internalize the effect of this effort on the IM's profit. The size and sign of this correction (with respect to the traditional Ramsey-Boiteux formula) depends on the difference between $a$ and $\omega_{1}$ (that is, between the price of access to the network and the marginal cost of infrastructure).

The second case we study is that of an unregulated monopoly. In this situation, the rail operator is free to choose both its effort and also its price on the final market. For a given price of the transport service, the condition which determines the optimal effort is identical to that observed above since in both cases the RO maximizes its profit. However, the optimality condition for the price of the service becomes now:

\footnotetext{
${ }^{10}$ As in the case of complete regulation, we suppose that financial transfers between the regulator and the industry are possible.
} 


$$
\frac{p-\left(\frac{\partial C_{e f}}{\partial y}+a \frac{\partial Y}{\partial y}\right)}{p}=\frac{1}{\varepsilon(p)}
$$

which corresponds to the classical monopoly optimality expression. We remark that in this case, knowledge of the (exogenous) behavior of the IM is no longer necessary as only the access price influences the endogenous variables chosen by the RO.

\section{Estimation}

As we do not directly observe the effort of the rail operator, we adopt the following steps. In both situations, that is to say the service supply regulation or the unregulated monopoly, the optimality condition in effort allows us to express the effort $e$ as a function of the observable variables $y$ and $a$. The effort obtained is then introduced into the cost equations, the engineering function, the demand function and the corresponding behavioral equations. Finally we proceed with the estimation of the associated equation systems using the method of nonlinear three stage least squares.

\section{Comments}

The results are gathered in Table 2. Note that, as with the preceding models which do not account for productivity effort, the quality of the estimations is nearly identical for the two cases. ${ }^{11}$ However, effort is a statistically significant variable. All the other variables are significant in the two scenarios, with the exception of $\omega_{0}$. Finally, we note that the introduction of a productivity effort for the RO does not significantly affect the likelihood of the model.

At this stage, the following facts seem to appear. First, the effort plays a meaningful role as the parameters $\phi$ and $\gamma_{2}$ that defines the optimal effort level are statistically significant. (See Equation 14.) Hence, accounting for these unobservable actions undertaken by the RO to improve its productivity is relevant to achieve a higher goodness-of-fit. Second, the two scenarios, namely supply service regulation or monopoly on the final sector, produce estimations with likelihood values that are not statistically different. A tentative explanation is that, as the rail operator provides both regulated and unregulated services, the high level of

\footnotetext{
${ }^{11}$ The observed difference in the estimates of the aggregate elasticity in these models (see Table 2) with respect to the earlier estimations (See Table 1) is in the large part due to the presence of the cost of public funds. However, the small number of observations can also explain in part the changes in the parameter estimates.
} 
aggregation of our data does not allow us to distinguish between the two polar cases of complete regulation and pure monopoly.

Table 2: Estimation of models under moral hazard and with fixed access charge

\begin{tabular}{|c|c|c|c|c|}
\hline \multirow[b]{2}{*}{ Parameter } & \multicolumn{2}{|c|}{ Supply service regulation (M3) } & \multicolumn{2}{|c|}{ Monopoly (M4) } \\
\hline & Value & t Value & Value & t Value \\
\hline$\alpha$ & 2.7977 & 7.72 & 11.7985 & 8.19 \\
\hline$\delta_{0}$ & -2.6687 & -63.18 & -1.6173 & -9.62 \\
\hline$\delta_{1}$ & 0.0093 & 5.81 & 0.0392 & 6.11 \\
\hline$\beta$ & 0.0080 & 27.31 & 0.0080 & 27.11 \\
\hline$\phi$ & 0.0232 & 5.53 & 0.0231 & 5.55 \\
\hline$\gamma_{0} / 10^{8}$ & 2.2041 & 9.16 & 2.2028 & 9.19 \\
\hline$\gamma_{1}$ & 0.1372 & 17.00 & 0.1374 & 17.11 \\
\hline$\gamma_{2} / 10^{11}$ & 7.14 & 6.09 & 7.12 & 6.14 \\
\hline$\omega_{0}$ & 18167702 & 1.97 & 17835416 & 1.84 \\
\hline$\omega_{1}$ & 6.36762 & 61.94 & 6.3714 & 59.05 \\
\hline Elasticity & 0.3414 & & 1.4396 & \\
\hline Effort & 0.1199 & & 0.1201 & \\
\hline Returns to scale & 3.1116 & & 3.1287 & \\
\hline RO's marginal cost & 0.0318 & & 0.0317 & \\
\hline Likelihood value & 3.0678 & & 3.0523 & \\
\hline
\end{tabular}

\section{Moral hazard models under endogenous access charge}

We have so far considered that the access tariff was exogenously given. In the context of regulation, this assumption is hard to justify. As the access price influences the behavior of the RO, access price-setting should be used by the regulator to correct for the non-internalized externalities. In this section, we follow the same methodology developed in the preceding section; however we now impose different rules on access pricing. ${ }^{12}$

\section{Budget-balanced access pricing}

An alternative access price rule is to set the price so as to balance the budget of the IM, i.e., the access price is determined so as to cover the infrastructure cost. Under this

\footnotetext{
${ }^{12}$ Another scenario could be that the access price is chosen so as to maximize social welfare. The results of this highly hypothetical case are reported in Appendix 3.
} 
assumption, we re-estimate the two reference models, i.e., the service supply regulation and the monopoly. The results are gathered in Table 4.

Some comments are called for. First, the assumption of an access price set to balance the budget significantly increases the quality of the estimation as, under both behavioral assumptions (monopoly and regulation), the likelihood value is lower; all the parameters are statistically significant; the behavioral assumption of an unregulated monopoly rail operator gives a slightly better statistical estimation in comparison to the assumption of a monopoly regulated on their service supply.

Table 4: Estimation of models under moral hazard and budget-balanced access pricing

\begin{tabular}{|c|c|c|c|c|}
\hline \multirow[b]{2}{*}{ Parameter } & \multicolumn{2}{|c|}{ Supply service regulation (M5) } & \multicolumn{2}{|c|}{ Monopoly (M6) } \\
\hline & Value & $t$ Value & Value & $t$ Value \\
\hline$\alpha$ & 2.6326 & 13.84 & 12.2043 & 11.54 \\
\hline$\delta_{0}$ & -2.6887 & -123.55 & -1.5723 & -13.00 \\
\hline$\delta_{1}$ & 0.0089 & 7.46 & 0.0412 & 6.85 \\
\hline$\beta$ & 0.0083 & 33.83 & 0.0086 & 32.83 \\
\hline$\phi$ & 0.0253 & 6.70 & 0.0299 & 6.34 \\
\hline$\gamma_{0} / 10^{8}$ & 2.2206 & 13.03 & 2.0776 & 12.47 \\
\hline$\gamma_{1}$ & 0.1375 & 25.32 & 0.1332 & 21.99 \\
\hline$\gamma_{2} / 10^{11}$ & 7.067 & 9.65 & 7.742 & 7.88 \\
\hline$\omega_{0} / 10^{8}$ & 1.1615 & 14.89 & 1.1714 & 14.01 \\
\hline$\omega_{1}$ & 4.1705 & 47.91 & 4.1606 & 44.85 \\
\hline Elasticity & 0.3212 & & 1.4891 & \\
\hline Effort & 0.1223 & & 0.1140 & \\
\hline Returns to scale & 3.1618 & & 2.6260 & \\
\hline RO's marginal cost & 0.0313 & & 0.0370 & \\
\hline Likelihood value & 2.7875 & & 2.7388 & \\
\hline
\end{tabular}

\section{Expert-based access pricing}

As we have highlighted a number of times, the data do not allow us to estimate the economic cost associated with the use of infrastructure. Our methodology has therefore assumed that the IM releases their infrastructure spending each year, and this spending is dependent on the traffic using the railway network. The "marginal spending", that is $\omega_{1}$ in our model, gives the marginal impact of traffic on the IM's spending and is at the heart of the externality, not internalized in a context of vertical separation, between the IM and the RO. 
Another approach consists in using "expert knowledge” to determine the value of the marginal cost of infrastructure. In the following estimations we therefore take the marginal cost of infrastructure to equal 1.3 euros per train-km. ${ }^{13}$ A priori, this parameter influences the estimation only in the case of the regulated monopoly. However, by removing the "weight" on the global estimation, and in freeing a variable which may now be used as an instrument, the use of an exogenous value for the marginal cost of infrastructure also affects the estimation in the unregulated monopoly scenario.

In the two estimations reported in Table 5, we consider the case of the RO exerting a productivity effort and the access price set to balance the budget based on the expert value for the marginal cost of infrastructure.

The main result is that for each scenario (monopoly or regulation) the parameter estimations are very similar. However, the use of expert knowledge slightly improves the results of our estimations, with a short advantage for the monopoly scenario. If one looks at the Vuong statistics reported in Table A1 of Appendix 1, these two scenarios dominate all others.

Table 5: Estimation of models under moral hazard and expert-based access pricing

\begin{tabular}{|c|c|c|c|c|}
\hline \multirow[b]{2}{*}{ Parameter } & \multicolumn{2}{|c|}{ Supply service regulation (M7) } & \multicolumn{2}{|c|}{ Monopoly (M8) } \\
\hline & Value & $t$ Value & Value & $t$ Value \\
\hline$\alpha$ & 2.4845 & 8.59 & 11.4010 & 8.02 \\
\hline$\delta_{0}$ & -2.7052 & -80.69 & -1.6638 & -10.04 \\
\hline$\delta_{1}$ & 0.0082 & 6.01 & 0.0379 & 5.97 \\
\hline$\beta$ & 0.0085 & 26.52 & 0.0085 & 25.96 \\
\hline$\phi$ & 0.0268 & 5.93 & 0.0261 & 5.86 \\
\hline$\gamma_{0} / 10^{8}$ & 2.1737 & 8.56 & 2.2017 & 8.81 \\
\hline$\gamma_{1}$ & 0.1368 & 16.08 & 0.1382 & 16.30 \\
\hline$\gamma_{2} / 10^{11}$ & 7.181 & 5.73 & 6.984 & 5.93 \\
\hline Elasticity & 0.3032 & & 1.3911 & \\
\hline Effort & 0.1212 & & 0.1242 & \\
\hline Returns to scale & 3.0295 & & 3.2164 & \\
\hline RO’s marginal cost & 0.0325 & & 0.0309 & \\
\hline Likelihood value & 2.0761 & & 2.0743 & \\
\hline
\end{tabular}

\footnotetext{
${ }^{13}$ This consists of the marginal cost of traffic management and maintenance, excluding replacement as this expense of the IM is not taken into account.
} 


\section{The case for the high speed train (HST)}

We repeat here the analysis but limit ourselves to data on the HST traffic for the same period. We consider the case where the RO exerts a productivity effort and the access price is set to balance the IM's budget on this specific service. The estimation results are collected in Table 6 which calls for the following remarks.

Table 6: Estimation of models under moral hazard and budget-balanced access pricing - The HST case

\begin{tabular}{crrrr}
\hline \multirow{2}{*}{ Marameter } & \multicolumn{2}{c}{ Supply service regulation } & \multicolumn{2}{c}{ Monopoly } \\
& \multicolumn{1}{c}{ Value } & $t$ Value & \multicolumn{1}{c}{ Value } & \multicolumn{1}{c}{ Value } \\
\hline$\alpha$ & 7.3078 & 4.11 & -1.0342 & -2.24 \\
$\delta_{0}$ & -2.4272 & -17.60 & 0.0717 & 3.85 \\
$\delta_{1}$ & 0.0207 & 3.81 & 0.0041 & 10.82 \\
$\beta$ & 0.0042 & 14.64 & 0.0455 & 2.42 \\
$\phi$ & 0.0741 & 2.10 & 26072954 & 1.63 \\
$\gamma_{0}$ & 12655729 & 0.88 & 0.0633 & 13.90 \\
$\gamma_{1}$ & 0.0597 & 15.45 & 2.064 & 1.81 \\
$\gamma_{2} / 10^{12}$ & 3.592 & 1.27 & 31535852 & 5.61 \\
$\omega_{0}$ & 35335494 & 8.47 & 6.8655 & 24.73 \\
$\omega_{1}$ & 6.6852 & 31.01 & & \\
\hline & & & 2.2430 & \\
\hline Elasticity & 0.6498 & & 0.0285 & \\
Effort & 0.0192 & & 1.2667 & \\
Returns to scale & 1.1002 & & 0.0455 & \\
RO’s marginal cost & 0.0524 & & 2.1675 & \\
\hline Likelihood value & 2.5258 & &
\end{tabular}

Firstly, the statistical estimation is significantly better for the two scenarios than for the corresponding models using the data for all types of traffic. (See Table 4.) This arises from the greater homogeneity of the data relative to the estimations based on all passenger traffic. Secondly, the most statistically relevant scenario is the one where the rail operator acts as an unregulated monopoly over the service supply. This seems coherent with the fact that the entrepreneurial freedom of the rail operator is much greater for HST traffic than for regulated services. Finally, the estimations of the price elasticity are significantly higher than those obtained by using the complete data, which suggests that competitive pressures are likely to be more important for HST traffic. 
Compared to the corresponding models using the data for all types of traffic which could not be statistically distinguished, the Vuong test statistic takes the value -3.92 indicating that the monopoly model with budget-balanced access pricing provides a better approximation of the data generating process than the supply regulation model.

\section{Conclusion}

The main contribution of this paper is to provide a methodology to estimate the parameters of the railways systems which are relevant to the evaluation of various policy reforms. The proposed methodology can be decomposed in the following steps.

First, we use the principles of the so-called new regulatory economics to determine several scenarios. A scenario corresponds to particular behaviors for the rail operator (regulation or monopoly position) and the infrastructure manager (pricing of access at the infrastructure marginal cost or to break even). The methodology can take into account unobservable variables like the rail operator's effort to improve its productivity or to better manage its demand. Each scenario leads to a set of equations which link the observable variables like the rail operator's cost and price and the infrastructure manager's cost and access price.

The second step consists in estimating the equations associated to a given scenario. This gives estimates for the structural parameters of the railway system, both on the cost side and on the demand side. Competing scenarios can be tested against each other following Vuong's methodology, in order to determine the one that fits best the data.

Two main lessons are drawn from this analysis. First, as the presence of unobservable efforts exerted by the RO to improve its productivity is statistically relevant in every scenario studied, one concludes that the RO is not fully regulated. This emphasizes that the design of policy reforms must account for the incentives they create on the RO. Second, the analysis also shows that the most statistically significant scenarios are the ones in which the access tariff imposed by the infrastructure manager is such that the revenue generated by the access tariff is equal to the infrastructure spending. The pricing of the access to the infrastructure network therefore does not seem to be governed by economic principles, but more by budget considerations. Having analyzed the limits and pitfalls of the current regulation of the French railway system, it should be possible to understand how to transpose the theoretical principles 
of incentive regulation and access pricing as developed in Laffont and Tirole (1990a, 1990b) to this situation.

Moreover, based on the knowledge of, on the one hand, the key structural parameters, i.e., marginal costs and demand elasticities, and, on the other hand, the behavior of the various actors at stake, simulations of various policy reforms are then possible. For instance, in our framework, it should be possible to simulate the impact of the entry of a competitor on the transport service market, a change of the rules that govern the pricing of access, the creation of a regulator.

For the results of such simulations to be meaningful and useful, we fully acknowledge that precise data are required. However, our methodology provides an economically-grounded objective and transparent way to assess various policy options. 


\section{Appendix 1: Specification Tests}

Each cell of Table A1 below provides the Vuong statistic of comparison between a Model 1 and a Model 2. If the statistic is lower than -2, model 2 is « better » than model 1 and vice versa is the statistic is lower than 2 . When the statistic is between -2 and 2 , we cannot conclude. The two models M1 and M2 referenced here correspond to the ones whose results are presented in Table 1 in the text, and so on.

\begin{tabular}{c|ccccccc}
\hline & \multicolumn{7}{|c}{ Model 1 } \\
Model 2 & M1 & M2 & M3 & M4 & M5 & M6 & M7 \\
\cline { 2 - 7 } M2 & 0.71 & & & & & \\
M3 & 0.05 & -0.02 & & & & \\
M4 & 0.02 & -0.04 & -0.49 & & & \\
M5 & -0.38 & -0.41 & -0.85 & -0.82 & & \\
M6 & -0.39 & -0.42 & -0.83 & -0.81 & -0.40 & & \\
M7 & -1.49 & -1.49 & -4.95 & -5.27 & -2.25 & -1.82 & \\
M8 & -1.47 & -1.47 & -4.99 & -5.35 & -2.23 & -1.82 & -0.13 \\
\hline
\end{tabular}

\section{Appendix 2: Derivation of the optimality conditions}

Here we explain how the equilibrium conditions are obtained in the different scenarios when the productivity effort is integrated into the model. The calculations are very similar for each scenario, and so we only study in detail here the case of a monopoly regulated on the service supply but not on its effort, and an access price to balance the budget for infrastructure.

The problem of the RO is given by:

$$
\max _{e} \pi_{e f}=p(y) y-a Y-C_{e f}(y, e)
$$

where $Y=(\beta-\phi e) y$ and $C_{e f}=\gamma_{0}+\left(\gamma_{1}-e\right) y+\frac{1}{2} \gamma_{2} e^{2}$. The first-order condition associated to this optimization problem is necessary and sufficient and allows us to express the productivity of the rail operator as a function of the service supply and the access price:

$$
e(y, a)=\frac{y(1+a \phi)}{\gamma_{2}}
$$

In our context, the regulation of the service supply and the access price has an impact on the rail operator's incentives to exert a more or less important productivity effort. 
We now look at the planner's problem. In the scenario under consideration, the planner controls only the rail operator's service supply and the subsidy given to the RO. The access price follows a rule to balance the budget. The planner's problem can then be formally written as follows:

$$
\begin{aligned}
& \max _{T_{e f}, y} W=S(y)-p(y) y+\left[\pi_{e f}+T_{e f}\right]+\left[\pi_{g i}\right]-(1+\lambda)\left(T_{e f}\right) \\
& \text { subject to : } \pi_{e f}+T_{e f} \geq 0, \quad \pi_{g i} \geq 0, \quad e(y, a)=\frac{y(1+a \phi)}{\gamma_{2}} .
\end{aligned}
$$

The planner's objective is strictly decreasing in the level of transfer to the rail operator, and so the optimal transfer is such that the participation constraint of the rail operator is binding. A balanced budget for the infrastructure implies that:

$$
\pi_{g i}=a Y-C_{g i}(Y)=0 \quad \text { soit } \quad a=\frac{\omega_{0}}{(\beta-\phi e) y}+\omega_{1} .
$$

Using these expressions for the access price and the transfer to the rail operator, we obtain the following revision of the planner's problem:

$$
\begin{gathered}
\max _{y} S(y)-p(y) y+(1+\lambda)\left[p(y) y-\omega_{0}-\omega_{1}(\beta-\phi e) y-\gamma_{0}-\left(\gamma_{1}-e\right) y-\frac{1}{2} \gamma_{2} e^{2}\right] \\
\text { subject to } e=\frac{y(1+a \phi)}{\gamma_{2}} .
\end{gathered}
$$

Optimization with respect to the service offer $y$ allows us to obtain the necessary optimality condition (which we assume to be sufficient) following some manipulation:

$$
\frac{p-\left[\omega_{1}(\beta-\phi e)+\gamma_{1}-e\right]}{p}=\frac{\lambda}{1+\lambda \varepsilon(p)}+\frac{1+a \phi}{\gamma_{2}} \frac{y}{p} \phi\left(a-\omega_{1}\right) \text {. }
$$

\section{Appendix 3: The socially optimal access price}

We consider here that the access price is chosen so as to maximize social welfare. In this case, one easily show that an access price equal to the "marginal cost of the IM" is optimal. ${ }^{14}$ Then, the price and effort that result from this hypothetical situation coincide with those that are socially optimal, that is to say, as in the case where the RO's effort can be chosen by the regulator. The intuition is that the rail operator does not internalize the impact of its productivity effort on the infrastructure manager's costs. To internalize this effect, it is enough to ensure that the access price transmits the correct price signal to the rail operator, which corresponds to an access price set at the marginal cost of infrastructure in our context.

\footnotetext{
${ }^{14}$ The equations characterizing this case are available from the authors upon request.
} 
In summary, the planner has then enough control variables at its disposition to ensure that the rail operator has the correct productivity incentives.

The estimation results are gathered in Table A3. Note that, in this case, we directly estimate the marginal cost of infrastructure. What most stands out here is that the quality of estimation has greatly decreased since the value of likelihood function is higher than the ones associated with the models presented in the text. (Recall that we use a least square method so that the objective is to minimize the likelihood function.) There are several reasons for this result. While the data only imperfectly reflects the economic cost of infrastructure, setting the access price at the marginal cost of infrastructure does not seem to be the more realistic behavioral scenario.

Table A3: Estimation of the supply service regulation model under moral hazard and socially optimal access pricing

\begin{tabular}{ccr}
\hline Parameter & Value & $t$ Value \\
\hline$\alpha$ & 2.5775 & 13.97 \\
$\delta_{0}$ & -2.6865 & -122.04 \\
$\delta_{1}$ & 0.0065 & 6.41 \\
$\beta$ & 0.0085 & 27.64 \\
$\phi$ & 0.0252 & 7.29 \\
$\gamma_{0} / 10^{8}$ & 2.2554 & 15.18 \\
$\gamma_{1}$ & 0.1407 & 28.96 \\
$\gamma_{2} / 10^{11}$ & 6.651 & 11.61 \\
$\omega_{1}$ & 5.3502 & 24.32 \\
\hline & & \\
\hline Elasticity & 0.3145 & \\
Effort & 0.1299 & \\
Returns to scale & 3.6312 & \\
RO’s marginal cost & 0.0279 & \\
\hline Likelihood value & 4.7084 & \\
\hline
\end{tabular}




\section{References}

Brocas, I., K. Chan and I. Perrigne (2006), "Regulation under Asymmetric Information in Water Utilities,” American Economic Review, Vol. 96, pp. 62-66.

Cour des Comptes (2008), Le réseau ferroviaire: Une réforme inachevée, une stratégie incertaine.

Ecole Polytechnique Fédérale de Lausanne (2007), Audit sur la répartition des capacités d'infrastructures.

Gagnepain, P. and M. Ivaldi (2002), "Incentive Regulatory policies: The Case of Public Transit Systems in France,” Rand Journal of Economics, Vol. 33, pp. 605-629.

Gasmi, F., J.J. Laffont and W.W. Sharkey (1995), "Incentive Regulation and the Cost Structure of the Local Telephone Exchange Network," Journal of Regulatory Analysis, Vol. 12, pp 5-25.

IGF-CGPC (2007), Rapport sur la tarification du réseau ferré national.

Laffont, J.J. and J. Tirole (1990a), “The Regulation of Multiproduct Firms: Part I: Theory,” Journal of Public Economics, Vol. 43, Issue 1, pp. 1-36.

Laffont, J.J. and J. Tirole (1990b), "The Regulation of Multiproduct Firms: Part II: Applications to competitive environments and policy analysis," Journal of Public Economics, Vol. 43, Issue 1, pp. 37-66.

Laffont, J.J. et J. Tirole (1993), A Theory of Incentives in Procurement and Regulation, MIT Press.

Meunier, D. and E. Quinet (2009), "Infrastructure charging and imperfect competition," mimeo.

Wolak, F.A. (1994), An Econometric Analysis of the Asymmetric Information RegulatorUtility Interaction,” Annales d'Economie et de Statistiques, Vol. 34, pp. 13-69.

Wunsch, P. (1994), "Estimating Menus of Linear Contracts for Mass Transit Firms.” WP CORE. 